\title{
Energy Cost of Living and Associated Pollution for Beijing Residents
}

\author{
Anders Arvesen, Jingru Liu, and Edgar G. Hertwich
}

\section{Keywords:}

China

greenhouse gas (GHG) emissions industrial ecology

household energy demand input-output analysis (IOA)

sustainable consumption

:// Supplementary material is available on the JIE Web site
Address correspondence to

Dr. Jingru Liu

Research Center for Eco-Environmental Sciences

Chinese Academy of Sciences

18 Shuangqing Road, Haidian District,

Beijing, 100085, China

liujingru@rcees.ac.cn

http://english.rcees.cas.cn/

(c) 2010 by Yale University

DOI: $10.1111 / \mathrm{j} .1530-9290.2010 .00265 . x$

Volume 14, Number 6
I

\section{Summary}

China's remarkable economic growth in the last 3 decades has brought about big improvements in quality of life while simultaneously contributing to serious environmental problems. The aim of all economic activities is, ultimately, to provide the population with products and services. Analyzing environmental impacts of consumption can be valuable for illuminating underlying drivers for energy use and emissions in society. This study applies an environmentally extended input-output analysis to estimate household environmental impact (HEI) of urban Beijing households at different levels of development. The analysis covers direct and indirect energy use and emissions of carbon dioxide $\left(\mathrm{CO}_{2}\right)$, sulfur dioxide $\left(\mathrm{SO}_{2}\right)$, and nitrogen oxide $\left(\mathrm{NO}_{x}\right)$. On the basis of observations of how $\mathrm{HEl}$ varies across income groups, prospects for near-future changes in $\mathrm{HEI}$ are discussed. Results indicate that in 2007, an urban resident in Beijing used, on average, 52 gigajoules of total primary energy supply. The corresponding annual emissions were 4.2 tonnes $\mathrm{CO}_{2}, 27$ kilograms $\mathrm{SO}_{2}$, and 17 kilograms $\mathrm{NO}_{x}$. Of this, only $18 \%$ to $34 \%$ was used or emitted by the households directly. While the overall expenditure elasticity of energy use is around 0.9 , there is a higher elasticity of energy use associated with transport. The results suggest that significant growth in $\mathrm{HEl}$ can be expected in the near future, even with substantial energy efficiency improvements. 


\section{Introduction}

Environmental gains achieved on the production side of the economy are often offset by increased demand (UNEP 2002). Partly in recognition of this threat, it has been argued that purely technological approaches are not sufficient to achieve sustainable development and that we also need to focus attention on lifestyle and consumer behavior (UN 2002). Residential buildings and private vehicles are commonly responsible for $20 \%$ to $50 \%$ of a country's total energy use. To understand the entire scope for changes in consumption, researchers must also include the energy required to produce the goods and services consumed by households, the indirect or embodied energy use, and associated emissions (Hertwich 2005). Thus, when investigating household environmental impacts (HEI), one studies not only the household consumption of electricity and fuels (i.e., direct impacts) but also the linkages between household activities and impacts generated in nonresidential sectors of the economy (i.e., indirect impacts). The HEI is hence valuable for identifying trade-offs and providing for a full picture of the "environmental footprint" of a household. One can calculate HEI by combining economic input-output tables with household expenditure data and direct energy or emissions data by industry sectors or on the basis of life cycle assessments. This method was first used in the 1970s by Herendeen and colleagues, who analyzed the energy requirements of U.S. (Herendeen and Tanaka 1976; Herendeen et al. 1981) and Norwegian (Herendeen 1978) households. In existing studies, shelter (energy goods used in households plus housing), mobility, and food are generally identified as important consumption categories (Hertwich 2005; Tukker and Jansen 2006; Hertwich and Peters 2009). The majority of studies of HEI have investigated developed countries, which raises the question of whether the general conclusions also hold for developing countries. The studies on India (Pachauri and Spreng 2002) and Brazil (Cohen et al. 2005) show that these two countries are quite different. A better understanding of how HEI varies across the globe and with different stages of development requires more work on developing countries. China is an important emerging economy, and Beijing is of particular interest, as it is wealthier than the rest of China. HEI studies have been used for priority setting in product policy-for example, in the European Union (EU) — and have become of interest to the work of the International Resource Panel.

China's economy has grown at a remarkable rate in the last 3 decades, which makes it possible for an increasing share of the Chinese population to enjoy an affluent lifestyle. Because they do not have to limit their consumption strictly to the necessities of life, an increasing number of Chinese citizens realize their aspirations to a life with diversified consumption, high levels of mobility, large flats, and numerous electrical appliances. These developments have contributed to improvements in quality of life. On the downside, increased economic activity has contributed to serious environmental problems (Liu and Diamond 2005), many of which are related to the country's energy system. In a global context, China's rapidly growing carbon dioxide $\left(\mathrm{CO}_{2}\right)$ emissions are a major reason for concern. China is approaching the United States as the world's largest emitter of $\mathrm{CO}_{2}$, and arguments have recently been made that forecasts of Chinese $\mathrm{CO}_{2}$ emissions generally underestimate the growth potential (Auffhammer and Carson 2008; Blanford et al. 2008). On a national and local level, there are concerns about local air pollutants. After 1978, gradual relaxations in restrictions on migration in China have allowed for rapid urbanization to occur (UNFPA 2007). At the national level, $43.9 \%$ of the population was living in urban areas in 2006, compared with $36.2 \%$ in 2000 and 26.4\% in 1990 (NBS 2007).

In this study, we apply an environmentally extended input-output analysis to estimate the HEI of Beijing households at different levels of wealth in 2007. We analyze the contribution of different consumption categories. Using observations of how HEI varies across income groups as a basis, we discuss prospects for near-future changes in HEI. The analysis includes household energy requirements and associated emissions of $\mathrm{CO}_{2}$, sulfur dioxide $\left(\mathrm{SO}_{2}\right)$, and nitrogen oxide $\left(\mathrm{NO}_{\mathrm{x}}\right)$. Improving our understanding of how lifestyles and human aspirations and needs relate to energy use and environmental impacts is important for several reasons. It may help in assessing future 
levels of environmental impacts, and it can provide scientists and decision makers with insights that are useful for reducing the burdens economic activities place on the environment. With continued urbanization and economic growth in China, substantial changes in consumption and lifestyles can be expected in the future. One rationale for studying the HEI of Beijing urban households is that urban households in Beijing are more affluent and own more goods than the urban national average. Thus, the lifestyles of urban Beijing residents today may be indicative of the lifestyles of a larger population in a more urbanized and wealthy near-future China. In light of the rate at which Chinese society changes; the severe environmental problems, which cause serious economic losses, social conflicts, and negative health impacts (Liu and Diamond 2005); the mixed energy efficiency picture, with much of China's industry still relying on inefficient and outdated technology (IEA 2007); and the profound implications that unchecked $\mathrm{CO}_{2}$ emissions in China are likely to have on the earth's climate, the provision of good scientific support for informed energy and environmental policies in China seems to be urgent and important.

There is a growing interest in the environmental impacts of Chinese consumption. Urbanization and the growth in consumption levels were identified as main drivers for increases in indirect HEI between 1992 and 2002, with efficiency improvements only partially offsetting the effects of consumption growth (Peters et al. 2007). Changes in consumption patterns were found to have little significance compared with consumption growth and efficiency improvements. Peters and colleagues (2006b) found that the per capita indirect energy use of households was 4.2 times greater for urban households compared with rural households. Wei and colleagues (2007) assessed both direct and indirect energy use and $\mathrm{CO}_{2}$ emissions of Chinese households. According to their results, the indirect energy requirements were 2.4 times greater than the direct energy use for urban households. In another study, Liang and colleagues (2007) used an eightregion input-output model to perform a scenario analysis on China's future energy requirements and $\mathrm{CO}_{2}$ emissions. The results show signifi- cant differences between consumption-based and production-based environmental impacts. For example, in the Beijing-Tianjin region in 2020, the emissions driven by consumption exceed the emissions generated within the region's geographical boundaries by $34 \%$.

Fan and colleagues (2007) presented an inputoutput-based model and accompanying software for analyzing future energy use and $\mathrm{CO}_{2}$ emissions in China. Computed results indicate exponential growth in energy use and emissions toward 2020, despite improvements in energy efficiency. In recent years, several studies evaluating $\mathrm{CO}_{2}$ embodied in international trade have focused on China. Explicitly taking regional technology differences into account, Peters and colleagues (2004) found that the majority of emissions in Norwegian consumption were embodied in imports, with large emissions originating from developing countries. In a similar study, emissions embodied in imports to the United Kingdom were found to increase by $82 \%$ over the period 1992-2004, with emissions generated in non-OECD economies, such as China, playing an increasingly important role (Wiedmann et al. 2008). In the case of the United States, the results of Weber and Matthews (2007) indicate a rapid growth from 1997 to 2004 in the $\mathrm{CO}_{2}$ emissions embodied in U.S. imports from China. This is mirrored by rapid increases in emissions embodied in China's exports since 1990 (Weber et al. 2008) and projections to 2030 (Guan et al. 2008).

\section{Background Information}

Unless otherwise indicated, information on household characteristics is derived from various editions of the Beijing and China statistical yearbooks (BMBS 1996-2008; NBS 2007). In the last 3 decades, there has been a rapid growth in consumption levels as well as major changes in consumption patterns in urban China, even more so in urban Beijing. The average total living expenditures in urban Beijing increased by $120 \%$ in the period from 1996 to 2006, given fixed prices based on the Beijing consumer price index. If one looks at income groups separately, the total living expenditures increased by $90 \%$ and $151 \%$ for the 
low-income and high-income households (first and fifth quintiles), respectively, which indicates a widening gap between the worst off and the best off. In 2006, the average urban resident in Beijing had a $70 \%$ higher living expenditure level than the national urban average, compared with $46 \%$ in 1996 . The greater spending power has been accompanied by big changes in urban Beijing residents' everyday lives. For example, from 1996 to 2006 the proportion of total expenditures spent on food decreased from $47 \%$ to $31 \%$, the average per capita floor space increased from 14 to $20 \mathrm{~m}^{2}$, and the average household size decreased from 3.06 to 2.90 persons per household. The greater spending power, combined with relaxing restrictions on private vehicle ownership, has led to substantial increases in private car ownership (Liu et al. 2007). In 2006, there were 18 automobiles per 100 households in urban Beijing, compared with 4.3 in urban China in general. Beijing urban households also own more electrical appliances than the national urban average. Whereas 100 urban households in China in 2006 owned, on average, 137 color televisions, 92 refrigerators, 97 clothes washers, and 88 air conditioners, the same number of Beijing urban households owned 155,105, 107, and 157, respectively. Given differences in ownership level across income groups in 2006, refrigerator ownership seemed to be approaching saturation in urban Beijing, as the high-income households (fifth quintile) owned only $6 \%$ more refrigerators than the low-income (first quintile) households. For clothes washers, color televisions, and air conditioners, respectively, the ownership rates were $13 \%, 23 \%$, and $48 \%$ greater for the highincome households than for the low-income households.

Beijing houses a large number of rural migrants, who officially are seen as temporary residents, although many of them remain year after year. It has previously been estimated that $60 \%$ of the temporary residents in Beijing live in enclaves of old farmhouses in the outer urban fringe (Gu and Shen 2003). In Beijing in 2007, the temporary residents numbered 4.2 million (BMBS 2008). The informal status of rural migrants leads to gaps in official statistics and implausible numbers for energy consumption.

\section{Methods}

Drawing on the work of Peters and colleagues (2006a), we set up an environmental inputoutput model to estimate indirect energy use of Beijing residents and associated emissions. The direct consumption of electricity, heat, and fuels and associated emissions are derived from energy statistics. Only urban households are included in the analysis.

\section{Direct Impacts}

The determination of direct HEI builds on two sources. (1) Data on residential energy consumption, population, household size, and expenditures in 2007 are collected from the 2008 Beijing Statistical Yearbook (BMBS 2008). (2) Factors for converting from mass to energy and emissions units are adopted from the work of Peters and colleagues (2006a), with original sources cited therein. BMBS (2008) presents residential energy consumption by six energy carriersnamely, electricity, heat, coal, gasoline, liquefied petroleum gas, and natural gas. The consumption of noncommercial energy is assumed to be negligible. The determination of direct HEI by income groups involves three steps. First, we determine total energy use for the average resident by dividing total residential consumption by the number of permanent residents living in urban areas (10.12 million). Conversions to standardized units are carried out according to the final recommendations of Peters and colleagues (2006a). Second, the total energy use is distributed among income groups according to each income group's expenditures in the 2007 Chinese Survey of Consumer Expenditure (SCE; BMBS 2008). Third, we estimate emissions values by multiplying energy values with emissions factors from the work of Peters and colleagues (2006a). It is not entirely clear to what extent the figures of residential energy consumption also cover the consumption of temporary residents. Presumably, temporary residents consume relatively small amounts of fuel for transport and rely largely on coal for heating and cooking. Assumptions are made to link categories for Beijing residential energy consumption (BMBS 2008) with the categories for household 
expenditures (BMBS 2008) and categories in the work of Peters and colleagues (2006a).

\section{Indirect Impacts}

Indirect emissions and energy use are calculated with input-output analysis (Miller and Blair 1985; Hertwich 2005). The Chinese inputoutput table is compiled by the Chinese National Bureau of Statistics (NBS) every 5 years. The 2007 table used in this study has 135 sectors. Household final demand is based on data from the 2007 SCE. Beijing-specific data from SCE, based on a sample of 3,000 urban households in Beijing, are available in the annual publication Beijing Statistical Yearbook. Living expenditures are divided into 64 consumption categories, of which six categories represent energy goods (electricity, coal, liquefied petroleum gas, pipeline gas, heat, and transport fuels and parts). The categorization of energy goods in the SCE corresponds fairly well with the breakdown of residential energy consumption into energy carriers in the energy statistics. It is assumed that expenditures on transport fuel constitute $90 \%$ of the fuels and parts category. The population is divided into five groups according to their income, each group representing $20 \%$ of the households sampled, with separate expenditure data presented for each socioeconomic group (BMBS 2008). The Beijing SCE does not include temporary residents. As the households that belong to temporary residents disproportionally constitute the lower end of the income distribution, the estimates of per capita indirect energy use are representative of the permanent population only and do not give a complete picture of the overall situation in Beijing. Some important characteristics of the five income groups are given in Supplementary Table S-2 in the Supplementary Material on the Web.

A construction of Chinese energy and pollution $\left(\mathrm{CO}_{2}, \mathrm{SO}_{2}, \mathrm{NO}_{\mathrm{x}}\right)$ data suitable for environmental input-output analysis is described by Peters and colleagues (2006a), and data for 2002 are available online. The input-output calculations presented in the current article are based on an updated data set that uses 2007 energy statistics and input-output tables. The data cover the use of 20 energy carriers by 43 energy sectors. In the original NBS energy statistics, transport services are aggregated with postal, storage, and telecommunication services. This aggregation is problematic due to the higher energy and emissions intensities of transport services. Adopting the approach of Peters and colleagues (2007), we make assumptions to disaggregate the original, aggregated industry sector and to allocate postal, storage, and telecommunications services to the sector "other." The indirect energy requirements for providing electricity and heat can be calculated according to input-output analysis but can also be estimated from the energy data. The latter method is preferred here, as it excludes uncertainties related to price variations. The indirect energy requirements of electricity and heat are calculated as direct energy multiplied with the indirect/direct ratio.

It is assumed that the national input-output tables and industry energy data are also representative for Beijing. Imports are assumed to be produced with domestic technology. Capital formation is treated as a final demand category. Assumptions are made to link economic sectors in the input-output tables with energy sectors and SCE categories. Although the inputoutput tables are in producers' prices (excluding value-added tax [VAT]), the SCE includes VAT and various consumption taxes. Due to a fairly complicated system, there is no definite and straightforward way to subtract taxes from the expenditure values. For simplicity, it is assumed that multiplying all expenditures by 0.95 removes VAT and other taxes.

\section{Results}

An average urban resident in Beijing uses 52 gigajoules (GJ) of total primary energy supply each year, causing emissions of 4.2 tonnes ${ }^{1} \mathrm{CO}_{2}$, 27 kilograms $(\mathrm{kg}) \mathrm{SO}_{2}$, and $17 \mathrm{~kg} \mathrm{NO}_{\mathrm{x}}$. Table 1 shows the distribution across consumption categories. Direct energy use, which includes the consumption categories "electricity, heat, and household fuels" and "fuel for transport," constitutes $34 \%$ of the total energy requirements of households. The most important categories in terms of total energy requirements are "electricity, heat, and household fuels" (21\%), "food and beverages" (16\%), "residence (excluding energy use 
Table I Annual household environmental impact (HEI) of an average urban resident in Beijing by main consumption categories (share of total)

\begin{tabular}{lcccc}
\hline Consumption category & Energy $(\%)$ & $\mathrm{CO}_{2}(\%)$ & $\mathrm{SO}_{2}(\%)$ & $\mathrm{NO}_{x}(\%)$ \\
\hline Electricity, heat, and household fuels & 21.3 & 18.0 & 17.6 & 12.6 \\
Fuel for transport & 12.7 & 10.5 & 0.3 & 14.6 \\
Food and beverages & 15.6 & 16.2 & 18.1 & 16.7 \\
Clothing and footwear & 5.6 & 5.9 & 7.0 & 6.2 \\
Transport (excluding fuels) & 6.7 & 7.7 & 7.7 & 8.4 \\
Communications & 2.6 & 2.8 & 3.6 & 3.0 \\
Household articles and services & 4.2 & 5.1 & 5.8 & 4.6 \\
Residence (excluding energy use in households) & 15.4 & 15.0 & 18.9 & 16.0 \\
Medicine and medical services & 4.9 & 5.3 & 6.2 & 5.5 \\
Culture and recreation & 5.3 & 6.0 & 7.0 & 6.0 \\
Education & 2.4 & 2.5 & 2.9 & 2.7 \\
Miscellaneous & 3.4 & 4.8 & 4.7 & 3.7 \\
Total & $\mathbf{5 2 ~ G J}$ & $4.2 \mathrm{t}$ & $27 \mathbf{~ k g}$ & $17 \mathrm{~kg}$ \\
\hline
\end{tabular}

Note: One gigajoule $(\mathrm{GJ})=10^{9}$ joules $(\mathrm{J}, \mathrm{SI})$; one tonne $(\mathrm{t})=10^{3}$ kilograms $(\mathrm{kg}, \mathrm{SI}) \approx 1.1$ short tons.

in households)" (15\%), and "fuel for transport" $(13 \%)$. Other (indirect) energy use of transport contributes $7 \%$. The seven remaining consumption classes represent between $2 \%$ and $6 \%$ each.

Table 2 shows direct and indirect components of household energy use, according to the results. The largest direct share of total energy is found for coal $(97 \%)$, followed by natural gas (94\%), fuel for transport (91\%), liquefied petroleum gas $(87 \%)$, and heat (72\%). For electricity the direct share is significantly lower (36\%).

Table 2 Direct use of energy carriers by Beijing households and the associated energy costs of producing and delivering the energy carriers to the households

\begin{tabular}{lcc}
\hline Energy carrier & $\begin{array}{c}\text { Direct } \\
\text { energy } \\
\text { use } \\
\text { (GJ/capita) }\end{array}$ & $\begin{array}{c}\text { Indirect } \\
\text { energy } \\
\text { requirements } \\
\text { (GJ/capita) }\end{array}$ \\
\hline Electricity & 3.1 & 5.4 \\
Coal & 1.5 & 0.05 \\
Liquefied petroleum gas & 1.0 & 0.1 \\
Natural gas & 3.3 & 0.3 \\
Heat & 2.1 & 0.8 \\
Fuel for transport & 6.6 & 0.6 \\
\hline
\end{tabular}

Note: One gigajoule $(\mathrm{GJ})=10^{9}$ joules $(\mathrm{J}, \mathrm{SI})$.
Figure 1 shows how HEI, in terms of energy requirements, varies across income groups. The highest income group requires 2.5 times more energy for living than the lowest income group. The expenditure elasticity of energy use is around 0.9. Similar values have been observed for Brazil and India, more than the typical 0.8 observed in developed countries (Lenzen et al. 2006). One striking trend is the high income elasticity of energy use associated with transport, with use of fuel for transport increasing from $2.8 \mathrm{GJ} /$ capita for the low-income and medium-income households to 13.3 GJ/capita for the high-income households. Energy use related to food and beverages; electricity, heat, and household fuels; and education is quite stable. Although the total expenditure level of the high-income households is 2.5 times greater than that of the low-income households, the direct use of energy in the households is only 1.3 times greater. As is evident from Supplementary Table S-6 in the Supplementary Material on the Web, however, the aggregation of electricity, heat, and household fuels into a single category masks some changes in the composition of direct energy use in households with income. Although electricity, natural gas, and heat consumption increase with rising income, the coal consumption of the high-income group is only $17 \%$ of that for the low-income group. Liquefied petroleum gas consumption also decreases with 


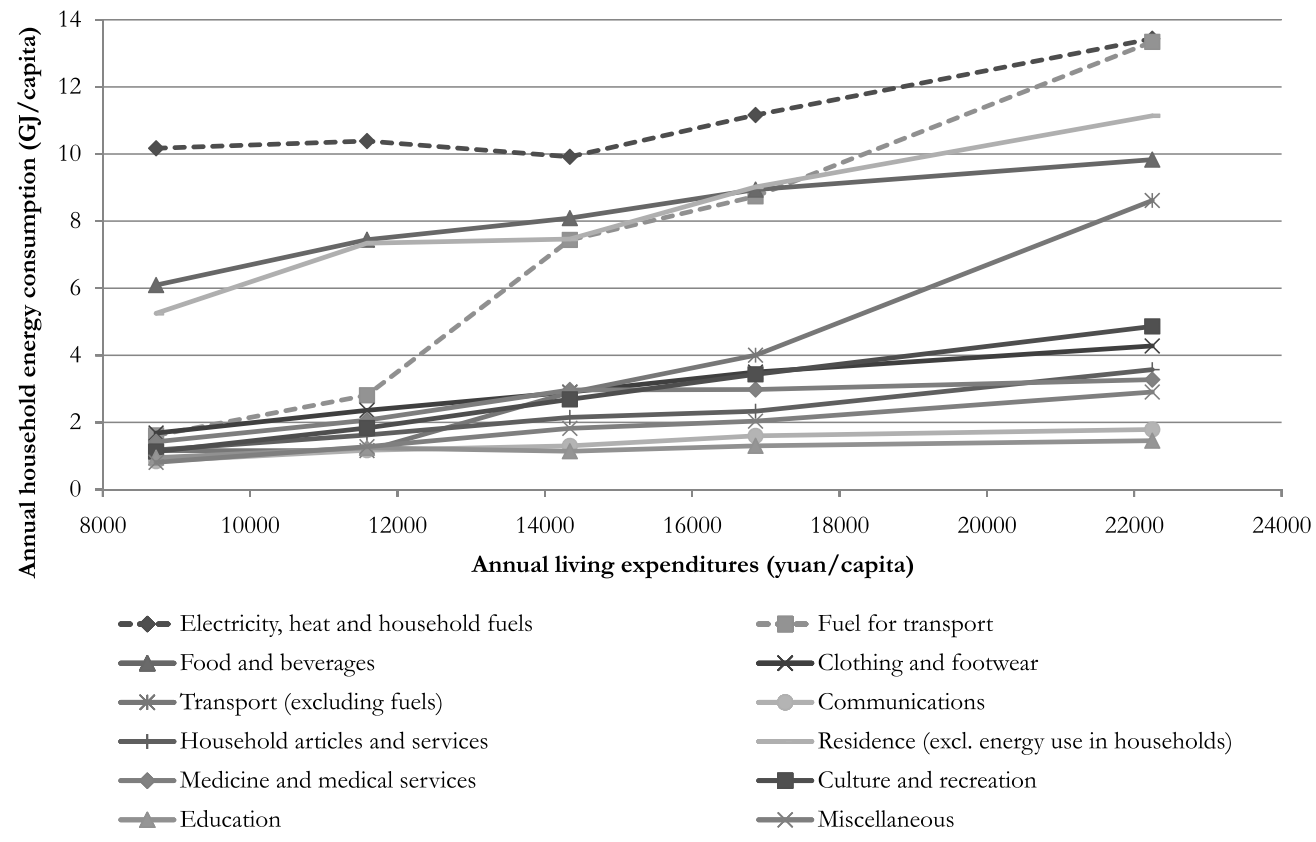

Figure I Annual household energy consumption by level of total living expenditures. Direct energy consumption categories are shown by dotted lines. One gigajoule $(\mathrm{G} J)=10^{9}$ joules $(\mathrm{J}, \mathrm{SI})$. Excl. $=$ excluding.

rising income. For clothing and footwear, household articles and services, culture and recreation, and miscellaneous expenditures, there is also a strong rise with income, although not as strong as for transport. The average energy intensity of consumption is $3.5 \mathrm{MJ} /$ yuan.

Combining observations of energy consumption in the reference year 2007 with assumptions on future growth in total expenditure level (Supplementary Table S-11 in the Supplementary Material on the Web), we conducted a simple exercise to project the energy consumption to 2015. We made the basic assumption that when populations become more affluent, they adopt the lifestyles of populations that already enjoy the higher level of affluence. Under this assumption, future growth in the average per capita income can be thought of as populations moving from one income group to another. Linear interpolation was used to establish intermediate values. Guided by observed income elasticities, we constructed an artificial "very high-income" group to represent households with incomes surpassing that of the high-income group of 2007.
With constant technology, per capita household energy consumption increases by a factor of 1.7 from 2007 to 2015 (figure 2). Transportrelated energy use constitutes about half of the increase. The Chinese government has set ambitious targets for reducing the energy intensity of society. The target of its 11th five-year plan is to achieve an annual reduction in energy intensity of $4.36 \%$ between 2006 and 2010 on the 2005 level (IEA 2007). In the longer term, the government has called for efforts to reach a GDP of \$US 4 trillion (2000 prices) by 2020 while only doubling energy consumption (Yang 2008), equivalent to reducing energy consumption per yuan by $3.4 \%$ annually. If it is assumed that an annual reduction in energy intensity of $3.4 \%$ is representative for HEI in Beijing in the time period 2007-2015, per capita household energy consumption increases with a factor of 1.3 (as opposed to 1.7 with constant technology). Hence, even with overall energy efficiency improvements corresponding to the central government's targets, there will be a significant growth in per capita HEI in urban Beijing, according to the results. 
Indirect $\quad$ Direct $\quad$ Total

2015 Beijing urban, with energy efficiency improvements

2015 Beijing urban, constant technology 2007 Beijing urban

2002 China urban (Wei et al. 2007)

2002 China rural (Peters et al. 2006b)

2002 China urban (Peters et al. 2006b)

1997 China urban (Peters et al. 2006b)
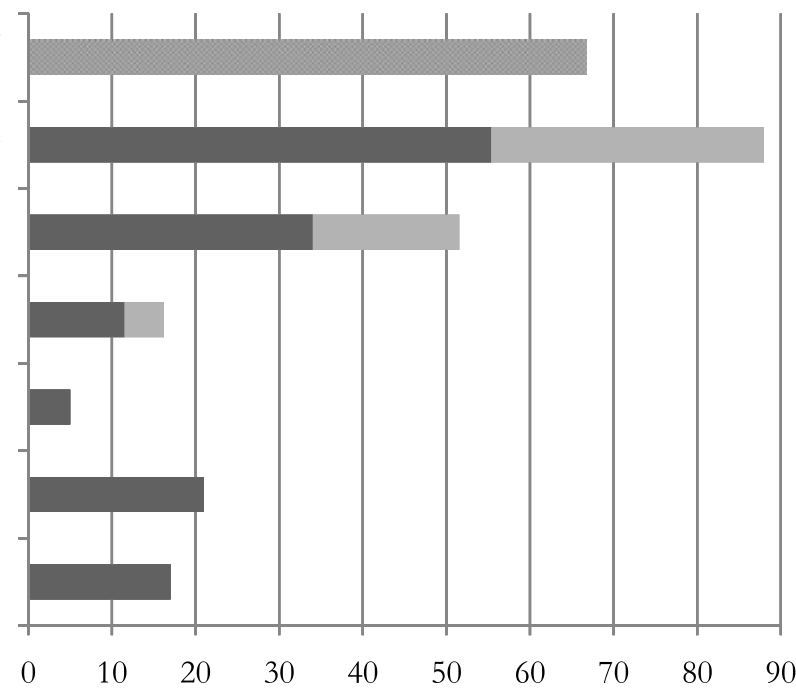

Household energy consumption (GJ/capita)

Figure 2 Annual household energy consumption 1997-2015. One gigajoule $(G)=10^{9}$ joules (J, SI). Peters and colleagues (2006b) include residential electricity and heat from fossil sources in their estimates of indirect household energy consumption. Numbers from the work of Wei and colleagues (2007) have been converted from tons of coal equivalents (tce) to GJ/capita with a conversion factor of $29.31 \mathrm{GJ} /$ tce and urban population number from official statistics.

The input-output calculation for China shows the great importance of gross capital formation for energy use (48\% of total; Supplementary Table S-3 and Supplementary Figure S-1 in the Supplementary Material on the Web). The environmental impacts of capital investments are largely caused by construction activities, which represent $57 \%$ to $64 \%$ of the total impact from investments. Investment in machinery represents about $30 \%$. Next to investments, urban household consumption is responsible for the largest share of energy use, followed by rural household consumption. Even though rural residents make up the majority of the Chinese population, 55\% in 2007, their impacts constitute only one quarter of the total household impacts. If we treat export instead of net trade as a final demand category, it is of slightly higher importance than total household consumption (Supplementary Table S-3 in the Supplementary Material on the Web). Governmental energy use is comparable in size to the energy use of households in rural areas.

\section{Discussion and Conclusions}

One must bear in mind the significant uncertainties when interpreting the results. Some uncertainties relate to fundamental challenges of input-output analysis, such as the use of domestic emissions inventory for imports and the treatment of capital formation as a final demand category. Others relate directly to assumptions and choices made in this particular study, such as our combination of national input-output tables to study households in Beijing, and still others relate to the uncertain quality of data sources. Data inconsistencies between China's energy statistics and the household surveys have previously been identified (Pachauri and Jiang 2008). Utilizing regional rather than national input-output tables would presumably give a more realistic representation of goods produced and consumed locally but would be less representative for goods produced with national production structure. Also worth noting is the uncertainty introduced by the 
presence of a large number of temporary residents in Beijing. Regarding coal, the low indirect share to total energy consumption (table 2) may partly be explained by the input-output model's failure to capture the indirect consumption of temporary residents, on the one hand, and an inclusion of temporary residents in the official figures on residential energy consumption, on the other hand. This will, to a lesser extent, be problematic for the other energy carriers, if one assumes that temporary residents consume relatively small amounts of fuel for transport and rely largely on coal for heating and cooking. As energy losses during conversion from primary to secondary energy forms (e.g., from coal to electricity) are accounted for only for fossil energy carriers, the direct share for electricity is slightly higher than the efficiency of fossil power generation. Graus and colleagues (2007) report an average power plant efficiency of $33 \%$ in Chinese fossil power generation in 2003.

When one moves across income levels, there is a progression from coal and bottled liquefied petroleum gas to heat, electricity, and piped natural gas, which replicates a pattern of an "energy transition" to higher quality fuels with economic development. This is in line with Pachauri and Jiang's (2008) findings for urban households at the national level, whose consumption of coal sharply declines with increasing income. A transition from coal and petroleum products to electricity, heat, and pipeline gas has occurred over time in developed countries, as identified, for example, by Vringer and Blok (2000) for the Netherlands and by Park and Heo (2007) for South Korea. A similar transition over time is also occurring in China (Pachauri and Jiang 2008). As for electricity consumption, refrigerators, television sets, and air conditioners are important appliances in urban Beijing and China (Brockett et al. 2002; Zhou et al. 2007; Murata et al. 2008). Given changes in ownership rates over time and across income in Beijing, it seems plausible that air conditioners will be the most important single electrical appliance contributing to increased residential electricity consumption in the near future. Other studies have demonstrated that improved energy efficiencies of electrical appliances may yield huge energy savings in China (Lu 2007; Lin and Rosenquist 2008; Murata et al. 2008). For example, according to the analysis of Lin and
Rosenquist (2008), energy standards for air conditioners may yield cumulative national energy savings of 330 billion kilowatt hours ( $\mathrm{kWh}$; approximately 1,200 petajoules [PJ]) by 2020 , with cumulative $\mathrm{CO}_{2}$ reductions almost adding up to the entire European commitment under the Kyoto regime. Similarly, there is a great potential to reduce building energy consumption in China by reducing unwanted heat and mass transfer from buildings (Yang and Kohler 2008).

Under the assumption that populations moving up in income adopt the lifestyles of the welloff today, future income growth will be accompanied by dramatic increases in transport-related energy use and emissions. Although moving the entire urban population of Beijing up in income corresponding to the high-income group would result in a $52 \%$ increase in total energy use, the demand for fuel for transport would double. The example is hypothetical but illustrates that Beijing, already struggling with vehicular emissions and traffic congestion, has a huge growth potential in private car transport. This conclusion is also supported by the fact that the average urban Beijing resident spends $6.4 \%$ of his or her available income on transport, whereas evidence from developed countries shows that the share of available income spent on transport increases with income until it stabilizes at $10 \%$ to $16 \%^{2}$ (Schafer and Victor 2000; WBCSD 2001). This calls for continued strong policy action to control vehicular emissions in Beijing. It has been shown that efficiency improvements and advances in technology are unlikely to be sufficient if increasing environmental impacts from private transport in Beijing are to be avoided (Liu et al. 2007). Thus, policies are needed both to stimulate the utilization of low-emitting cars and to canalize future growth in mobility toward nonmotorized transport means or public transport. Focusing on providing affordable public transport services, as opposed to encouraging private car transport, will also be beneficial to the poorest residents (Ahmed et al. 2008).

The estimated share of direct energy use to total energy use of urban Beijing households is 34\%, which is higher than what has previously been estimated for urban China in 2002 (29\%; Wei et al. 2007) but comparable to or lower than most estimates for other countries (e.g., $40 \%$ for South 
Korea in 2000 [Park and Heo 2007], 39\% for Brazil in 1995-1996 [Cohen et al. 2005], and 34\% to $64 \%$ in 11 European countries in 1994 [Reinders et al. 2003]). Consumers' indirect energy use is substantial because the energy intensity per unit value added is high. Policy approaches to reduce indirect energy use and associated emissions address the energy efficiency of production and distribution of goods and services. A proper pricing of energy, including its externalities, would make energy costs a more important share of the total costs of goods.

The input-output analysis for China shows that capital investments are a major cause of energy use and emissions at the national level. As the economy matures, the importance of capital formation can be expected to decline. Due to expanded investments in rural areas, however, capital formation will continue to be a major cause of emissions in China also in the coming 2 decades (Guan et al. 2008). ${ }^{3}$ The projections suggest that even if one does not take population growth and urbanization into account, and with overall energy efficiency improvements roughly corresponding to the national government's targets, there will be a significant growth in HEI in urban Beijing in the near future. Undoubtedly, solving China's environmental problems is a formidable challenge that needs to be met by strong and informed policy action.

\section{Acknowledgements}

This work was supported in part by funding from the Department of Energy and Process Engineering at the Norwegian University of Science and Technology and by the Chinese National Scientific Foundation (Grant No. 70873122). We thank Dr. Dabo Guan for the provision of data.

\section{Notes}

1. The term tonne refers to metric tons. One tonne $=$ $10^{3}$ kilograms $(\mathrm{kg}, \mathrm{SI}) \approx 1.1$ short tons.

2. The one exception to this rule is Japan, where the share spent on transport has stabilized at $7 \%$ to $8 \%$, which reflects dense population and more developed public transport systems (Schafer and Victor 2000; WBCSD 2001).
3. For more in-depth analyses of how the contribution of different final demand categories to energy use and emissions in China has changed and is expected to change, see the work of Peters and colleagues (2007) and Guan and colleagues (2008).

\section{References}

Ahmed, Q. I., H. Lu, and S. Ye. 2008. Urban transportation and equity: A case study of Beijing and Karachi. Transportation Research Part A: Policy and Practice 42(1): 125-139.

Auffhammer, M., and R. T. Carson. 2008. Forecasting the path of China's $\mathrm{CO} 2$ emissions using province-level information. Journal of Environmental Economics and Management 55(3): 229247.

Blanford, G. J., R. G. Richels, and T. F. Rutherford. 2008. Revised emissions growth projections for China: Why post-Kyoto climate policy must look east. Discussion paper 08-06. Cambridge, MA: Harvard Project on International Climate Agreements. http://belfercenter.ksg.harvard.edu/publication/ 18581/revised_emissions_growth_projections_ for_china.html. Accessed 11 December 2008.

BMBS. 1996-2008 various editions. Beijing statistical yearbook. Beijing Municipal Bureau of Statistics. Beijing, China: China Statistics Press.

BMBS. 2008. Beijing statistical yearbook. Beijing Municipal Bureau of Statistics. Beijing, China: China Statistics Press.

Brockett, D., D. Fridley, J. Lin, and J. Lin. 2002. A tale of five cities: The China residential energy consumption survey. In American Council for an Energy-Efficient Economy's Summer Study on Energy Efficiency in Buildings. Lawrence Berkeley National Laboratory. http://china.lbl.gov/ publications/tale-five-cities-china-residentialenergy-consumption-survey. Accessed 10 June 2009.

Cohen, C., M. Lenzen, and R. Schaeffer. 2005. Energy requirements of households in Brazil. Energy Policy 33(4): 555-562.

Fan, Y., Q.-M. Liang, Y.-M. Wei, and N. Okada. 2007. A model for China's energy requirements and $\mathrm{CO}_{2}$ emissions analysis. Environmental Modelling BS Software 22(3): 378-393.

Graus, W. H. J., M. Voogt, and E. Worrell. 2007. International comparison of energy efficiency of fossil power generation. Energy Policy 35(7): 39363951.

Gu, C. and J. Shen. 2003. Transformation of urban socio-spatial structure in socialist market 
economies: The case of Beijing. Habitat International 27(1): 107-122.

Guan, D., K. Hubacek, C. L. Weber, G. P. Peters, and D. M. Reiner. 2008. The drivers of Chinese $\mathrm{CO}_{2}$ emissions from 1980 to 2030. Global Environmental Change 18(4): 626-634.

Herendeen, R. A. 1978. Total energy cost of household consumption in Norway, 1973. Energy 3(5): 615630.

Herendeen, R. A. and J. Tanaka. 1976. Energy cost of living. Energy 1(2): 165-178.

Herendeen, R. A., C. Ford, and B. Hannon. 1981. Energy cost of living, 1972-73. Energy 6(12): 14331450.

Hertwich, E. G. 2005. Life cycle approaches to sustainable consumption: A critical review. Environmental Science and Technology 39(13): 4673-4684.

Hertwich, E. G. and G. P. Peters. 2009. The carbon footprint of nations: A global, trade-linked analysis. Environmental Science and Technology 43(16): 6414-6420.

IEA. 2007. World energy outlook 2007: China and India insights. Paris: International Energy Agency.

Lenzen, M., M. Wier, C. Cohen, H. Hayami, S. Pachauri, and R. Schaeffer. 2006. A comparative multivariate analysis of household energy requirements in Australia, Brazil, Denmark, India and Japan. Energy 31(2-3): 181-207.

Liang, Q.-M., Y. Fan, and Y.-M. Wei. 2007. Multiregional input-output model for regional energy requirements and $\mathrm{CO}_{2}$ emissions in China. Energy Policy 35(3): 1685-1700.

Lin, J. and G. Rosenquist. 2008. Stay cool with less work: China's new energy-efficiency standards for air conditioners. Energy Policy 36(3): 1090-1095.

Liu, J. and J. Diamond. 2005. China's environment in a globalizing world. Nature 435(7046): 1179_ 1186.

Liu, J., R. Wang, and J. Yang. 2007. A scenario analysis of Beijing's private traffic patterns. Journal of Cleaner Production 15(6): 550-556.

Lu, W. 2007. Potential energy savings and environmental impacts of energy efficiency standards for vapor compression central air conditioning units in China. Energy Policy 35(3): 1709-1717.

Miller, R. E. and P. D. Blair. 1985. Input-output analysis: Foundations and extensions. Englewood Cliffs, NJ: Prentice Hall.

Murata, A., Y. Kondou, M. Hailin, and Z. Weisheng. 2008. Electricity demand in the Chinese urban household-sector. Applied Energy 85(12): 11131125 .

NBS (National Bureau of Statistics of China). 2007. China statistical yearbook. National Bureau of
Statistics of China. Beijing, China: China Statistics Press.

Pachauri, S. and L. Jiang. 2008. The household energy transition in India and China. Energy Policy 36(11): 4022-4035.

Pachauri, S. and D. Spreng. 2002. Direct and indirect energy requirements of households in India. Energy Policy 30(6): 511-523.

Park, H.-C. and E. Heo. 2007. The direct and indirect household energy requirements in the Republic of Korea from 1980 to 2000: An input-output analysis. Energy Policy 35(5): 2839-2851.

Peters, G., T. Briceno, and E. Hertwich. 2004. Pollution embodied in Norwegian consumption. Trondheim, Norway: Norwegian University of Science and Technology (NTNU), Industrial Ecology Programme (IndEcol). www.ntnu.no/indecol/ publications/reports. Accessed 10 June 2009.

Peters, G. P., C. Weber, and J. Liu. 2006a. Construction of Chinese energy and emissions inventory. Trondheim, Norway: Norwegian University of Science and Technology (NTNU), Industrial Ecology Programme (IndEcol). www.ntnu.no/indecol/ publications/reports. Accessed 10 June 2009.

Peters, G. P., J. Liu, E. G. Hertwich, and R. Wang. 2006b. Drivers for energy consumption in Chinese households. Paper presented at the ninth biennial conference of the International Society for Ecological Economics on "Ecological Sustainability and Well-being," 15-18 December, New Delhi, India.

Peters, G. P., C. L. Weber, D. Guan, and K. Hubacek. 2007. China's growing $\mathrm{CO}_{2}$ emissions: A race between increasing consumption and efficiency gains. Environmental Science and Technology 41(17): 5939-5944.

Reinders, A. H. M. E., K. Vringer, and K. Blok. 2003. The direct and indirect energy requirement of households in the European Union. Energy Policy 31(2): 139-153.

Schafer, A. and D. G. Victor. 2000. The future mobility of the world population. Transportation Research Part A: Policy and Practice 34(3): 171-205.

Tukker, A. and B. Jansen. 2006. Environmental impacts of products: A detailed review of studies. Journal of Industrial Ecology 10(3): 159-182.

UN. 2002. World summit on sustainable development: Plan of implementation. New York, NY: United Nations Department of Economic and Social Affairs, Division for Sustainable Development.

UNEP. 2002. Sustainable consumption: A global status report. Paris: United Nations Environment Programme, Division of Technology, Industry and Economics. 
UNFPA (United Nations Population Fund). 2007. State of the world population 2007: Unleashing the potential of urban growth. New York, NY: United Nations Population Fund.

Vringer, K. and K. Blok. 2000. Long-term trends in direct and indirect household energy intensities: A factor in dematerialisation? Energy Policy 28(10): 713-727.

WBCSD (World Business Council for Sustainable Development). 2001. Mobility 2001: World mobility at the end of the twentieth century and its sustainability. World Business Council for Sustainable Development, Sustainable Mobility Working Group. www.wbcsd.org/web/projects/mobility/ english_full_report.pdf. Accessed 11 December 2008.

Weber, C. L. and H. S. Matthews. 2007. Embodied environmental emissions in U.S. international trade, 1997-2004. Environmental Science and Technology 41(14): 4875-4881.

Weber, C. L., G. P. Peters, D. Guan, and K. Hubacek. 2008. The contribution of Chinese exports to climate change. Energy Policy 36(9): 3572-3577.

Wei, Y.-M., L.-C. Liu, Y. Fan, and G. Wu. 2007. The impact of lifestyle on energy use and $\mathrm{CO}_{2}$ emission: An empirical analysis of China's residents. Energy Policy 35(1): 247-257.

Wiedmann, T., R. Wood, M. Lenzen, J. Minx, D. Guan, and J. Barrett. 2008. Development of an embedded carbon emissions indicator: Producing a time series of input-output tables and embedded carbon dioxide emissions for the UK by using a
MRIO data optimisation system. London, UK: Stockholm Environment Institute, University of York, and Centre for Integrated Sustainability Analysis, University of Sydney. http://resourceaccounting.org.uk/reports. Accessed 4 May 2009.

Yang, M. 2008. China's energy efficiency target 2010. Energy Policy 36(2): 561-570.

Yang, W. and N. Kohler. 2008. Simulation of the evolution of the Chinese building and infrastructure stock. Building Research $\mathcal{E}$ Information 36(1): 119.

Zhou, N., M. A. McNeil, D. Fridley, J. Lin, L. Price, S. de la Rue du Can, J. Sathaye, and M. Levine. 2007. Energy use in China: Sectoral trends and future outlook. LBNL-61904. Berkeley, CA: Lawrence Berkeley National Laboratory, Environmental Energy Technologies Division.

\section{About the Authors}

Anders Arvesen is a $\mathrm{PhD}$ student in industrial ecology at the Department of Energy and Process Engineering at the Norwegian University of Science and Technology (NTNU). Jingru Liu is an associate professor at the Research Center for Eco-Environmental Sciences, Chinese Academy of Sciences in Beijing. Edgar Hertwich is professor at the Department of Energy and Process Engineering, NTNU, and director of the Industrial Ecology Programme.

\section{Supplementary Material}

Additional Supplementary Material may be found in the online version of this article:

Supplement S1: This supplementary material provides additional background information and documentation on energy use in China.

Please note: Wiley-Blackwell is not responsible for the content or functionality of any supplementary materials supplied by the authors. Any queries (other than missing material) should be directed to the corresponding author for the article. 